\title{
FROM HAZARD TO RISK
}

Jana Sillmann, Simone Russo, Sebastian Sippel, and Kristina Alnes

T o better guide adaptation and mitigation decision-making on addressing the risk of climate change, novel and interdisciplinary approaches are required (Zwiers et al. 2013) that involve a dialogue between scientists from different communities (e.g., climate and impact modeling) and stakeholders from various sectors. Impactrelevant metrics need to be developed to analyze risk related to physical climate change, and thus to support stakeholders in the use and interpretation of climate data. For example, the Center for International Climate Research's (CICERO) Shades of Risk tool helps investors identify the most eminent risks from climate change by grading physical climate risks by region. A simple three-color system reflects whether impacts are observed and likely to increase (red), expected in the next decade (orange), or by midcentury (yellow). Investors can use the tool to focus on the most severe risks to their portfolio from climate change (Clapp et al. 2017). In this context, the Intergovernmental Panel on Climate Change (IPCC) definition of risk (e.g., IPCC 2012) provided the implicit basis for the discussions at the Workshop on Indicators for Climate Extremes and Socio-Economic Impacts under Different Emission Targets, ${ }^{1}$ which

AFFILIATIONS: SILLMANN AND ALNES-Center for International Climate Research, Oslo, Norway; Russo-European Commission, Joint Research Centre, Ispra, Italy; SIPPEL-Norwegian Institute of Bioeconomy Research, Ås, Norway

CORRESPONDING AUTHOR: Jana Sillmann,

jana.sillmann@cicero.oslo.no

DOI:10.I175/BAMS-D-17-0327.I

In final form 6 March 2018

(C) 2018 American Meteorological Society

For information regarding reuse of this content and general copyright

information, consult the AMS Copyright Policy.
WORKSHOP ON INDICATORS FOR CLIMATE EXTREMES AND SOCIO-ECONOMIC IMPACTS UNDER DIFFERENT EMISSION TARGETS
WHAT: This workshop brought together expert sci- entists from climate sciences, statistics, health, agriculture, and economics to discuss how to move beyond traditional climate indicators de- scribing climate-related hazards to more impact- relevant indicators for quantifying climate risk.
WHEN: 4-6 October 2017
WHERE: Ispra, Italy

was held at the European Commission Joint Research Center in Ispra, Italy, in fall 2017. Risk is therein defined as a product of the occurrence probability of an extreme event and its consequences, which depend on the vulnerability and exposure of the affected system.

Physical climate change is already observed in many regions of the world and increasingly challenge decision-makers (IPCC 2013). However, it is very difficult to translate changes in the intensity, duration, and frequency of weather and climate extremes (i.e., hazards) into actual risks for specific sectors and/or locations, or, even further, to express these in quantitative terms, mainly because we lack sufficient knowledge of the socioeconomic and environmental implications, including data on vulnerabilities and exposure (IPCC 2012).

Building on Future Earth's Workshop on Extreme Events and Environments and WCRP's Workshop on Addressing the Challenge of Compound Events,

\footnotetext{
${ }^{1}$ This workshop was co-organized by the Joint Research Center (JRC) and CICERO as part of the implementation of the World Climate Research Programme (WCRP) Grand Challenge on Weather and Climate Extremes.
} 
this workshop aimed at facilitating practical discussions on climate-related impacts to be expected for different emission scenarios, knowledge gaps and indicators that can facilitate decision-making on climate risk mitigation, and adaptation planning across various sectors. A range of approaches toward impact-relevant or climate risk indicators were presented at the workshop, such as the combination of indicators of climate extremes (e.g., Sillmann et al. 2013) and their extension to sector-specific climate indices (https://github.com/ARCCSS-extremes /climpact2) with aspects of vulnerability and exposure (e.g., Forzieri et al. 2016, 2017). Examples from climate econometrics were shown to illustrate how climate data can be linked to economic data (e.g., Hsiang 2016; Burke et al. 2015), and examples from the health sector included mortality risk estimates from extreme temperatures (Gasparrini et al. 2015) or considered critical thresholds for human-perceived heat (Russo et al. 2017). In addition, the development of more sophisticated hazard indicators related to compound events-that is, combinations of different hazards with impact relevance (see, e.g., Zscheischler et. al 2018)-were discussed as a complementary route toward more impact-relevant hazard metrics (e.g., Zscheischler et al. 2017), even in the absence of a formalized connection to scale- and system-specific vulnerability and exposure data.

\section{CRITERIA FOR COMPREHENSIVE RISK} INDICATORS. Clearly emerging from the workshop discussions is the idea that early engagement of the target audience (i.e., stakeholders) is essential i) to identify what is a useful risk indicator and ii) to develop mutual understanding between stakeholders and scientists. In the context of sustainable development, these two general properties (usefulness described as saliency and mutual understanding described as legitimacy), in addition to the adequacy of scientific methods of inquiry as such (credibility), have been found as key determinants of societally relevant scientific information (Cash et al. 2003).

In addition to these criteria of societal relevance, the workshop discussions revealed the need for a basic set of technical criteria to provide both accurate and robust estimates for risk arising from climate extremes-at present and in the future-under climate change scenarios. In principle, indicators need to be i) measurable, ii) monitorable, iii) validatable, and iv) transferable in terms of methodology (see also Fig. 1).

- Measurable: Indicators, or all relevant variables (or proxies) to derive the indicators, should be related to parameters that can be measured in an unambiguous way.

- Monitorable: Measurements can be upscaled to a monitoring program across space and time, providing the basis for estimating trends and other statistical measures.

- Validatable: Indicators can be, and actually are, regularly compared to and cross validated against existing observations (e.g., real-world impact data or established vulnerability measures, such as dose-response relationships; see example below).

- Transferable: Indicator methodologies should be transferable to different sectors and/or locations. Indicators based on methodologies without the ability to scale, while potentially interesting to a specific stakeholder group, do not contribute to the necessary advancement of the global discourse.

The technical development of comprehensive risk indicators is, however, complicated because of the complex and multilevel nature of the individual risk components. In particular, challenges lie in quantifying vulnerability (see the "Methodological challenges" section) and open-access availability of data (see the "Data challenges" section), and maintaining a continuous transdisciplinary dialogue between stakeholders and climate-impact scientists (see the "Communication challenges" section), which are described in more detail below.

CHALLENGES. Methodological. Bringing measures of vulnerability together with hazard is not straightforward. It emerged from the workshop discussions that a necessary condition for a vulnerability measure is that it accounts for temporal dynamics in vulnerability, and thus by extension risk estimates. Vulnerability can change between day and night, in the course of a season, and in the long term. Vulnerability in some cases can be considered as a transient phenomenon associated with exposure to particular risk, or it is a systematic chronic state. Ideally, reliable data to build a robust dose-response relationship (e.g., as in Gasparrini et al. 2017) would be needed in combination with scenarios of socioeconomic development, including projections of exposure- or vulnerability-relevant variables [e.g., population distribution, per capita gross domestic product (GDP); Riahi et al. 2017] that can be coherently matched to future hazard outcomes under different forcing pathways (O’Neill et al. 2016). The translation of those into a full-fledged risk analysis into the future, especially one including the effects of autonomous and climate change adaptation options 
(see, e.g., Bosello et al. 2006), would still remain challenging. Empirical quantification of climate change adaptation practices is under active research-for instance, in the U.S. residential sector (Cohen et al. 2017) - which could potentially be included in vulnerability estimates. Furthermore, vulnerability indicators are usually related to specific sectors, and it remains to be explored to what extent scientific methodologies can be transferred from one field to another. The same question applies to extrapolation of estimates across spatial scales.

Data. The weather and climate community [e.g., World Meteorological Organization (WMO) Commission for Climatology] has put substantial effort into measuring and monitoring climate variables, such as temperature and precipitation, across the world over the last decades (Zhang et al. 2011). This has also enabled assessment of changes in temperature and precipitation extremes in near- and long-term future observations (Donat et al. 2013), despite ongoing challenges in data acquisition and rescue (Brunet and Jones 2011). Likewise, long-term monitoring networks are in place for environmental variables (e.g., Baldocchi et al. 2001), and disaster impacts are recorded routinely (Guha-Sapir et al. 2016). Bringing these datasets together could provide exciting opportunities to investigate risk in a more comprehensive manner. Recent landmark agreements, such as the Sendai Framework for Disaster Risk Reduction (www.unisdr.org/we/coordinate/sendai -framework), have now also initiated a monitoring mechanism with a set of 38 indicators to measure progress against global targets and trends in reducing disaster risk and losses, which are also aligned with relevant Sustainable Development Goals (SDGs; also known as Global Goals for Sustainable Development, set by the United Nations).

Despite this progress, considerable challenges remain, among them a fundamental question on the appropriate use of daily-scale extreme data [e.g., from models from phase 5 of the Coupled Model Intercomparison Project (CMIP5)] for impact calculations (Sippel et al. 2016). Challenges also apply to observational data, for instance, related to estimating changes in global temperatures since the preindustrial period (Hawkins et al. 2017), or to overcoming the proprietary nature of some datasets. For example, while some companies in the insurance industry provide public loss databases (e.g., Sigma Explorer, www.sigma-explorer.com; NatCatSERVICE, www.munichre.com/en/reinsurance/business/non -life/natcatservice/index.html), the insurance

\section{Societal Relevance Criteria}

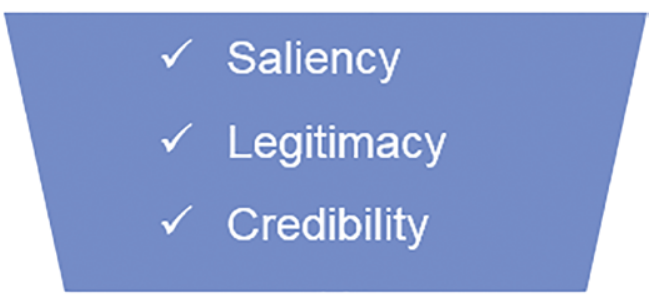

Technical criteria

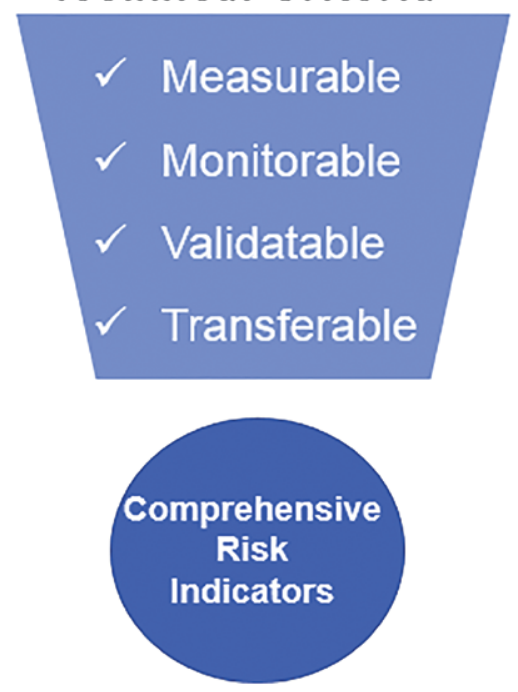

Fig. I. Conceptual illustration of the criteria for a scientifically and societally relevant comprehensive risk indicator.

industry mostly keeps detailed datasets on the economic impact of natural hazards proprietary.

Communication. Terminological differences exist between the different scientific fields, for example, exposure in the field of epidemiology refers to a hazard agent, while in the IPCC terminology hazard and exposure would be separated. Terminological differences also complicate communication between scientists and stakeholder groups with their own terminologies. For example, investors' understanding of risk usually narrowly refers to the likelihood of an investment returning less than its expected value.

A key discussion topic during the workshop was how to cross-fertilize the field by usefully combining or transferring disciplinary methodologies and tools. Some frameworks have already been developed and are used in disciplinary fields. For instance, a recent study used the IPCC definition of risk to quantify drought-induced risks of plant growth reductions based on a probabilistic approach (Van Oijen et al. 2013). 
Communicating with different target audiences often requires some "translation" work on behalf of scientists. Many important stakeholder groups require a reduction in the level of scientific complexity or for results to be presented in different formats. For example, a policy maker deciding on flood resilient infrastructure needs information on which areas are most likely to be at the highest risk but might not require or understand an analysis of area flood risk under different emission scenarios. The key challenge of such translation work is to communicate clear and simple messages while maintaining accuracy. The workshop discussions also revealed a particular concern that uncertainties might be marginalized or oversimplified.

CONCLUSIONS. In the absence of a unifying methodology to bring together vulnerability and hazards, as well as other "methodology challenges," a flexible and creative approach to creating new risk indicators is required. This cross-sectoral workshop highlighted several methodological approaches and showed that indicators can be powerful communication tools to reach important stakeholder groups (focusing on health, agriculture, and the investment sector). In particular, methodological approaches that are based on a close stakeholder dialogue and articulated needs appear promising. A combination of empirical, often local, disaster and vulnerability data with broad-scale estimates of climatic risk could provide a sense of risk under climatic changes. By monitoring over time, it might be possible to understand how risks develop, and this understanding in turn could be used to (cross) validate such empirical doseresponse relationships.

However, several remaining challenges were outlined that are broadly related to communication, methods, and data. For example, simple communication tools cannot always take into account the full complexity of system responses and associated uncertainties. Scientists have a responsibility to communicate the range of uncertainties to stakeholders to avoid creating a sense of precision that cannot be justified. Moreover, indicators do not necessarily need to be "risk indicators" to be useful. For some sectors, indicators of the physical climate hazard might be more tangible depending on stakeholder needs and expectations, precisely because of the outlined communication and data challenges.

Risk indicators should help with monitoring how various entities (e.g., communities, countries, companies) are prepared for more frequent and severe extreme climate hazards in the future. Uncertainty in the data and analyses used for the assessment of risks is inescapable, and it needs to be carefully considered in the context of risk indicators. Uncertain information can often be better than no information. For example, a measure of the direction of risk can sometimes be enough to provide useful information in some decision-making contexts.

In conclusion, to provide both accurate and robust risk estimates for climate change, new indicators should meet technical criteria, such as being measurable, monitorable, validatable, and transferable, to be scientifically relevant in addition to being salient, legitimate, and credible for the target audience.

ACKNOWLEDGMENTS. We thank all the participants of the workshop for their contributions. We also thank Ed Hawkins and Claudia Tebaldi for their comments on this meeting summary. J. Sillmann and K. Alnes are supported by the ClimINVEST project, which is part of European Research Area for Climate Services (ERA4CS), a European Research Area Network (ERANET) initiated by the Joint Programming Initiative Connecting Climate Knowledge for Europe (JPI Climate), and funded by the Research Council of Norway (RCN), the National Agency for Research (ANR) in France, and the Netherlands Organisation for Scientific Research (NWO) with cofunding by the European Union (Grant 690462).

\section{REFERENCES}

Baldocchi, D., and Coauthors, 2001: FLUXNET: A new tool to study the temporal and spatial variability of ecosystem-scale carbon dioxide, water vapor, and energy flux densities. Bull. Amer. Meteor. Soc., 82, 2415-2434, https://doi.org/10.1175/1520 $-0477(2001) 082<2415$ :FANTTS $>2.3 . C O ; 2$.

Bosello, F., R. Roson, and R. S. Tol, 2006: Economy-wide estimates of the implications of climate change: Human health. Ecol. Econ., 58, 579-591, https://doi .org/10.1016/j.ecolecon.2005.07.032.

Brunet, M., and P. Jones, 2011: Data rescue initiatives: Bringing historical climate data into the 21st century. Climate Res., 47, 29-40, https://doi.org/10.3354 /cr00960.

Burke, M., J. Dykema, D. B. Lobell, E. Miguel, and S. Satyanath, 2015: Incorporating climate uncertainty into estimates of climate change impacts. Rev. Econ. Stat., 97, 461-471, https://doi.org/10.1162 /REST_a_00478.

Cash, D. W., W. C. Clark, F. Alcock, N. M. Dickson, N. Eckley, D. H. Guston, J. Jäger, and R. B. Mitchell, 2003: Knowledge systems for sustainable development. Proc. Natl. Acad. Sci. USA, 100, 8086-8091, https://doi.org/10.1073/pnas.1231332100. 
Clapp, C., H. F. Lund, B. Aamaas, and E. Lannoo, 2017: Shades of climate risk: Categorizing climate risk for investors. CICERO Climate Finance Center Rep. 2017:01, 45 pp.

Cohen, F., M. Glachant, and M. Söderberg, 2017: The cost of adapting to climate change: Evidence from the US residential sector. Centre for Climate Change Economics and Policy Working Paper 297, and Grantham Research Institute on Climate Change and the Environment Working Paper 263, 64 pp.

Donat, M. G., L. V. Alexander, H. Yang, I. Durre, R. Vose, and J. Caesar, 2013: Global land-based datasets for monitoring climatic extremes. Bull. Amer. Meteor. Soc., 94, 997-1006, https://doi.org/10.1175/BAMS-D-12-00109.1.

Forzieri, G., and Coauthors, 2016: Multi-hazard assessment in Europe under climate change. Climatic Change, 137, 105-119, https://doi.org/10.1007/s10584 -016-1661-x.

—, A. Cescatti, F. Batista e Silva, and L. Feyen, 2017: Increasing risk over time of weather-related hazards to the European population: A data-driven prognostic study. Lancet Planet. Health, 1, e200-e208, https:// doi.org/10.1016/S2542-5196(17)30082-7.

Gasparrini, A., and Coauthors, 2015: Mortality risk attributable to high and low ambient temperature: A multicountry observational study. Lancet, 386, 369375, https://doi.org/10.1016/S0140-6736(14)62114-0.

— , and Coauthors, 2017: Projections of temperaturerelated excess mortality under climate change scenarios. Lancet Planet. Health, 1, e360-e367, https:// doi.org/10.1016/S2542-5196(17)30156-0.

Guha-Sapir, D., P. Hoyois, P. Wallemacq, and R. Below, 2016: Annual disaster statistical review 2016: The numbers and trends. Centre for Research on the Epidemiology of Disasters Rep., 80 pp.

Hawkins, E., and Coauthors, 2017: Estimating changes in global temperature since the preindustrial period. Bull. Amer. Meteor. Soc., 98, 1841-1856, https://doi .org/10.1175/BAMS-D-16-0007.1.

Hsiang, S., 2016: Climate econometrics. Annu. Rev. Resour. Econ., 8, 43-75, https://doi.org/10.1146/annurev -resource-100815-095343.

IPCC, 2012: Managing the Risks of Extreme Events and Disasters to Advance Climate Change Adaptation. Cambridge University Press, 582 pp.

_, 2013: Climate Change 2013: The Physical Science Basis. Cambridge University Press, 1535 pp., https:// doi.org/10.1017/CBO9781107415324.
O’Neill, B. C., and Coauthors, 2016: The Scenario Model Intercomparison Project (ScenarioMIP) for CMIP6. Geosci. Model Dev., 9, 3461-3482, https:// doi.org/10.5194/gmd-9-3461-2016.

Riahi, K., and Coauthors, 2017: The shared socioeconomic pathways and their energy, land use, and greenhouse gas emissions implications: An overview. Global Environ. Change, 42, 153-168, https://doi .org/10.1016/j.gloenvcha.2016.05.009.

Russo, S., J. Sillmann, and A. Sterl, 2017: Humid heat waves at different warming levels. Sci. Rep., 7, 7477, https://doi.org/10.1038/s41598-017-07536-7.

Sillmann, J., V. V. Kharin, F. W. Zwiers, X. Zhang, and D. Bronaugh, 2013: Climate extremes indices in the CMIP5 multimodel ensemble: Part 2. Future climate projections. J. Geophys. Res., 118, 2473-2493, https:// doi.org/10.1002/jgrd.50188.

Sippel, S., and Coauthors, 2016: A novel bias correction methodology for climate impact simulations. Earth Syst. Dyn., 7, 71-88, https://doi.org/10.5194/esd-7 -71-2016.

Van Oijen, M., C. Beer, W. Cramer, A. Rammig, M. Reichstein, S. Rolinski, and J.-F. Soussana, 2013: A novel probabilistic risk analysis to determine the vulnerability of ecosystems to extreme climatic events. Environ. Res. Lett., 8, 015032, https://doi.org /10.1088/1748-9326/8/1/015032.

Zhang, X., L. Alexander, G. C. Hegerl, P. Jones, A. K. Tank, T. C. Peterson, B. Trewin, and F. W. Zwiers, 2011: Indices for monitoring changes in extremes based on daily temperature and precipitation data. Wiley Interdiscip. Rev.: Climate Change, 2, 851-870, https://doi.org/10.1002/wcc.147.

Zscheischler, J., R. Orth, and S. I. Seneviratne, 2017: Bivariate return periods of temperature and precipitation explain a large fraction of European crop yields. Biogeosciences, 14, 3309-3320, https://doi .org/10.5194/bg-14-3309-2017.

— , and Coauthors, 2018: Future climate risk from compound events. Nature Climate Change, 8, 469-477, https://doi.org/10.1038/s41558-018-0156-3.

Zwiers, F. W., and Coauthors, 2013: Climate extremes: Challenges in estimating and understanding recent changes in the frequency and intensity of extreme climate and weather events. Climate Science for Serving Society, G. Asrar and J. Hurrell, Eds., Springer, 339-389. 


\section{AMS BOOKS RESEARCH APPLICATIONS HISTORY}

CLIMATE

The Thinking Person's Guide to Climate Change ROBERT HENSON

This fully updated and expanded revision of The Rough Guide to Climate Change combines years of data with recent research. It is the most comprehensive acknowledging controversies but standing strong in its stance that the climate is changing-and something needs to be done.

(c) 2014, PAPERBACK, 520 PAGES,

ISBN: 978-1-935704-73-7

LIST \$30 MEMBER \$20 overview of climate science,

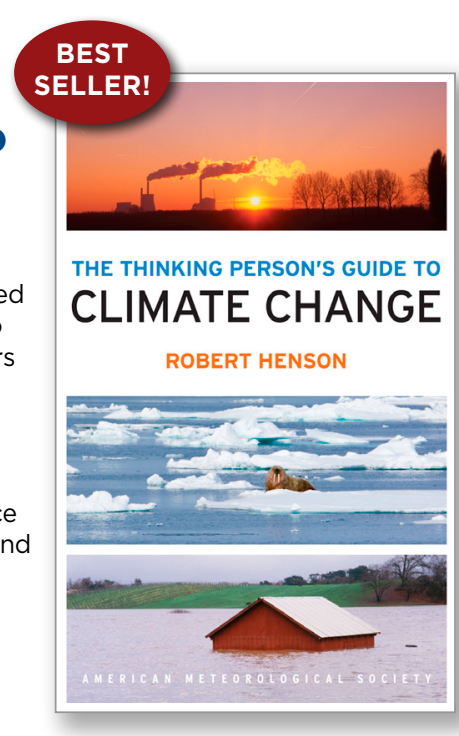

\section{Climate Conundrums:} What the Climate Debate Reveals about Us

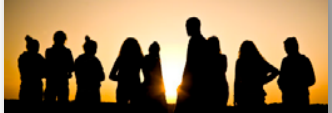

WILLIAM B. GAIL

This is a journey through how we think, individually and collectively, about humanity's relationship with nature, and more. Can we make nature better? Could science and religion reconcile? Gail's insights on such issues help us better understand who we are and find a way forward.

(c) 2014, PAPERBACK, 240 PAGES, ISBN: 978-1-935704-74-4 LIST \$30 MEMBER \$20
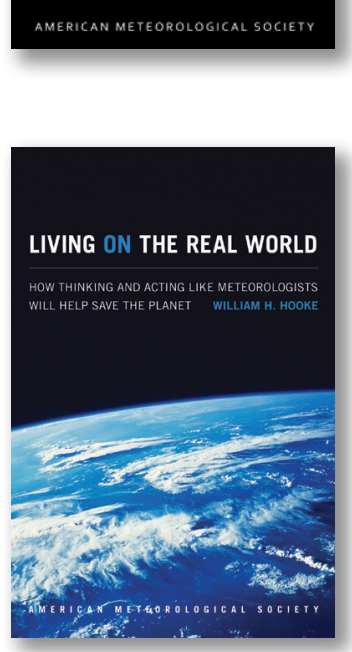

\section{Living on the}

\section{Real World:}

How Thinking and Acting Like Meteorologists

Will Help Save the Planet WILLIAM H. HOOKE

Meteorologists focus on small bits of information while using frequent collaboration to make decisions. With climate change a reality, William $\mathrm{H}$. Hooke suggests we look to the way meteorologists operate as a model for how we can solve the 21st century's most urgent environmental problems.

(c) 2014, PAPERBACK, 272 PAGES, ISBN 978-1-935704-56-0 LIST \$30 MEMBER \$22

\section{Synoptic-Dynamic Meteorology Lab Manual:}

Visual Exercises to Complement Midlatitude Synoptic Meteorology

\section{GARY LACKMANN, BRIAN E. MAPES, AND KEVIN R. TYLE}

These labs link theoretical concepts with groundbreaking visualization to elucidate concepts taught in the award-winning companion textbook by Gary Lackmann, Midlatitude Synoptic Meteorology.

(c) 2017, PAPERBACK, 126 PAGES, ISBN 978-1-878220-26-4 LIST \$80 MEMBER \$60 STUDENT \$50

\section{GUIDES}

\section{An Observer's Guide to Clouds}

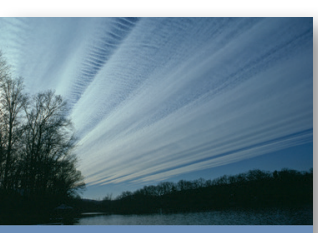

AN OBSERVER'S GUIDE CLOUDS AND WEATHER A NORTHEASTERN PRIMER ON PREDICTION

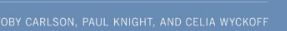
and Weather:

A Northeastern Primer on Prediction

TOBY CARLSON, PAUL KNIGHT, AND CELIA WYCKOFF

With help from Penn State experts, start at the beginning and go deep. This primer, intended for both serious enthusiasts and new meteorology students, will leave you with both refined observation skills and an understanding of the complex science behind the weather: the ingredients for making reliable predictions of your own. It connects fundamental meteorological concepts with the processes that shape

weather patterns, and will make an expert of any dedicated reader.

(c) 2014, PAPERBACK, 210 PAGES,

ISBN: 978-1-935704-58-4 LIST \$30 MEMBER \$20

\section{Eloquent Science:}

A Practical Guide to Becoming a Better Writer, Speaker, and Atmospheric Scientist DAVID M. SCHULTZ

The ultimate communications manual for undergraduate and graduate students as well as researchers in the atmospheric sciences and their intersecting disciplines.

(C) 2009, PAPERBACK, 440 PAGES,

ISBN 978-1-878220-91-2

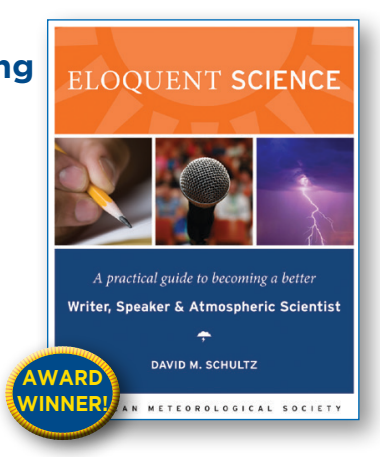

LIST \$45 MEMBER \$30 


\section{SHIPPING + DISCOUNTS AT BOOKSTORE.AMETSOC.ORG}

NEW

Verner Suomi: The Life and Work of the Founder of Satellite Meteorology

JOHN M. LEWIS WITH JEAN M. PHILLIPS, W. PAUL MENZEL, THOMAS H. VONDER HAAR, HANS MOOSMÜLLER, FREDERICK B. HOUSE, AND MATTHEW G. FEARON

Born in a Minnesotan mining town, Suomi would spend his best years next door in Wisconsin, but not before seeing the whole world-from space, that is. This is the story of the scientist, inventor, and teacher who founded satellite meteorology, written by

members of the communities that grew up around his groundbreaking work.

LIST \$3O MEMBER \$20

(c) 2016, PAPERBACK, 240 PAGES, ISBN: 978-1-944970-22-2

\section{Weather in the Courtroom: Memoirs from a Career iForensic Meteorology}
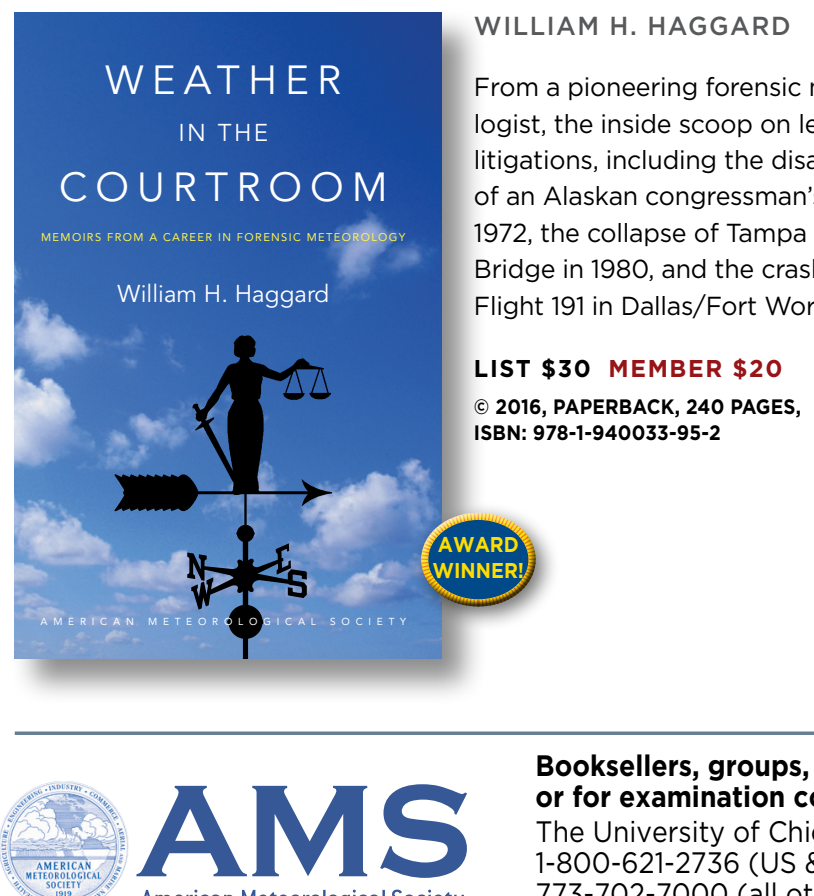

American Meteorological Society

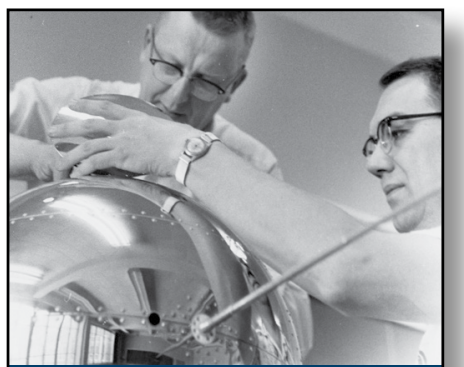

Verner Suomi

The Life and Work of the Founder of Satellite Meteorology

John M. Lewis with Jean M. Phillips,
W Paul Menzel, Thomas H. Vonder Haar, Hans Moosmill

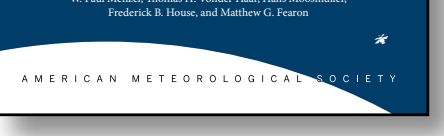

HISTORY

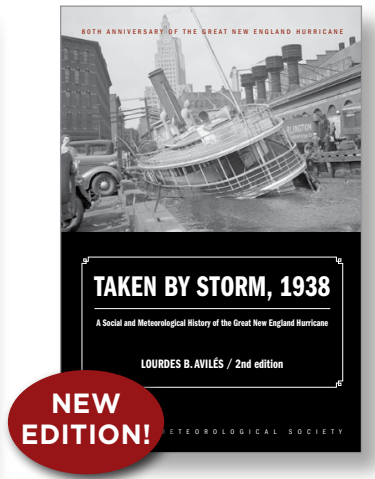

Taken by Storm, 1938:

A Social and Meteorological History of the Great New England Hurricane, 2nd Ed. LOURDES B. AVILÉS

The science behind 80 TH
ANNIVERSARY
AF OF STORM the 1938 Hurricane, which hit New England unannounced, is presented here for the first time along with new data that

sheds light on the motivations of the Weather Bureau forecasters. This compelling history successfully weaves science, historical accounts, and social analyses to create a comprehensive picture of the most powerful and devastating hurricane to hit New England to date.

c) 2018, PAPERBACK, 288 PAGES, ISBN: 978-1-944970-24-6 LIST \$30 MEMBER \$20

\section{A Scientific Peak:}

How Boulder Became a World Center for Space and Atmospheric Science

JOSEPH P. BASSI

How did big science come to Boulder, Colorado? Joe Bassi introduces us to the characters, including Harvard sun-Earth researcher Walter Orr Roberts, and the unexpected brew of politics, passion, and sheer luck that during the Cold War era transformed this "Scientific Siberia" to home of NCAR and NOAA.

(c) 2015, PAPERBACK, 264 PAGES, ISBN: 978-1-935704-85-0 LIST PRICE: $\$ 35.00$ MEMBER PRICE: $\$ 25.00$

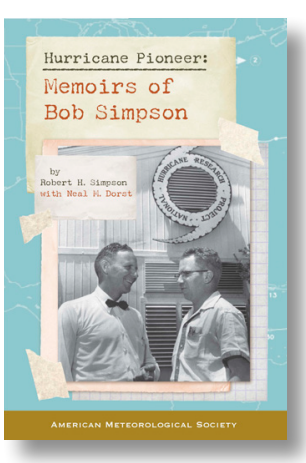
Hurricane Pioneer: Memoirs of Bob Simpson ROBERT H. SIMPSON AND NEAL DORST

In 1951, Bob Simpson rode a plane into a hurricane-just one of the many pioneering exploits you'll find in these memoirs. Bob and his wife Joanne are meteorological icons: Bob was the first director of the National Hurricane Research Project and a director of the National Hurricane Center. He helped to create the Saffir-Simpson Hurricane Scale; the public knows well his Categories 1-5. Proceeds from this book help support the AMS's K. Vic Ooyama Scholarship Fund.

(C) 2015, PAPERBACK, 156 PAGES

ISBN: 978-1-935704-75-1 LIST \$25 MEMBER \$2O 
